\title{
EDITORIAL
}

\section{Tumor homologous recombination deficiency assays: another step closer to clinical application?}

\author{
Shane R Stecklein ${ }^{1}$ and Priyanka Sharma ${ }^{2^{*}}$ \\ See related research by Vollebergh et al. http://breast-cancer-research.com/content/16/3/R47
}

\begin{abstract}
Inherited and acquired defects in homologous recombination, a phenotype termed 'BRCAness', may lend to therapeutic exploitation in breast cancer. To this end, development and clinical evaluation of platforms to identify signatures of BRCAness are of immense interest. In this issue of Breast Cancer Research, Vollebergh and colleagues report that a BRCA-like array comparative genomic hybridization (aCGH) genomic instability signature is associated with benefit from high-dose cyclophosphamide-thiotepa-carboplatin chemotherapy. We discuss the strengths and weaknesses of this study and consider the clinical significance and applicability of this aCGH BRCAness signature in the context of other existing homologous recombination deficiency detection platforms.
\end{abstract}

In this issue of Breast Cancer Research, Vollebergh and colleagues [1] report on the predictive capacity of an array comparative genomic hybridization $(\mathrm{aCGH})$ signature resembling BRCA1 - and BRCA2-mutant breast cancers. The BRCA1 and BRCA2 genes are required for DNA double-strand break (DSB) and interstrand crosslink repair by homologous recombination (HR) [2,3]. Pre-clinical and clinical data suggest that cancers arising in BRCA1 and BRCA2 mutation carriers are particularly responsive to agents that lead to DSBs (for example, platinum salts and poly(ADP-ribose) polymerase (PARP) inhibitors) [4-6]. Although inherited mutations in BRCA1 and BRCA2 account for only $5 \%$ to $10 \%$ of all breast cancers, these and other genes which operate in the HR pathway may be altered by mutation,

\footnotetext{
* Correspondence: psharma2@kumc.edu

${ }^{2}$ Division of Hematology/Oncology, Department of Internal Medicine, University of Kansas Medical Center, 2330 Shawnee Mission Parkway, MS5003, Westwood, KS 66205, USA

Full list of author information is available at the end of the article
}

rearrangement, DNA methylation, or attenuated mRNA expression, resulting in impairment of HR in a significant proportion of patients with breast cancer. Inactivation of HR by these mechanisms in $B R C A$-wild-type cancers (a phenotype termed 'BRCAness') may induce a similar hypersensitivity to DNA-damaging agents which can be therapeutically exploited. To this end, development and clinical evaluation of platforms to identify signatures of BRCAness have recently been a subject of intense investigation, especially in triple-negative breast cancer (TNBC), a subtype thought to be enriched for BRCAness [7-9].

Vollebergh and colleagues retrospectively assessed a subset of HER-2-negative tumor specimens from a randomized clinical trial that compared five cycles of 5-fluorouracil-epirubicin-cyclophosphamide $\left(\mathrm{FE}_{90} \mathrm{C}\right)$ with four cycles of $\mathrm{FE}_{90} \mathrm{C}$ followed by high-dose cyclophosphamide-thiotepa-carboplatin (HD-CTC) with autologous stem cell support in patients with at least four positive axillary lymph nodes. The BRCA1- and $B R C A 2$-like aCGH profiles were based on previous work by this group and were generated on 249 HER-2negative formalin-fixed paraffin-embedded (FFPE) tumor samples [10]. Overall, the $B R C A$-like ${ }^{\text {cgh }}$ profile was detected in $32 \%$ (12\% BRCA1-like, $15 \%$ BRCA2-like, and $5 \%$ both BRCA1- and BRCA2-like) of the study cohort and predicted benefit from HD-CTC in both TNBC and hormone receptor-positive breast cancer. HD-CTC was associated with improved overall survival compared with $\mathrm{FE}_{90} \mathrm{C}$ in patients with $B R C A$-like ${ }^{\mathrm{cgh}}$ tumors but not in patients with non-BRCA-like $\mathrm{e}^{\mathrm{cgh}}$ tumors. As expected, a significant proportion (76\%) of TNBCs harbored the $B R C A$-like $\mathrm{e}^{\mathrm{cgh}}$ profile. Interestingly, $28 \%$ of hormone receptor-positive tumors also demonstrated the $B R C A$ like ${ }^{\text {cgh }}$ profile. This aCGH platform is attractive as it allows detection of genomic instability resulting from HR deficiency without requiring identification of the precise molecular etiology. If validated in other cohorts, this 
assay could potentially identify patients destined to benefit from intensified DNA-damaging therapy.

Despite the future potential of this aCGH platform as a predictive marker, the present study has important limitations. First, the HD-CTC regimen included both carboplatin and intensified alkylating chemotherapy (cyclophosphamide and thiotepa) and therefore it remains unclear whether the benefit observed in the $B R C A$-like ${ }^{\mathrm{cgh}}$ patients within the experimental cohort was due to the platinum or the intensified alkylating agents or both. This is a significant confounder and complicates interpretation of these data. Additionally, although this study included a high-risk population (at least four positive nodes), neither the experimental (HD-CTC) nor the control (taxane-devoid chemotherapy) regimens are considered standard for node-positive breast cancer in this era. Evaluation of this assay in cohorts treated with contemporary neoadjuvant chemotherapy regimens is encouraged.

Currently, a standard platform for detecting BRCAness has not reached routine clinical application, but several functional assays besides the aCGH platform described by Vollebergh and colleagues have emerged. The homologous recombination deficiency (HRD) assay developed by Myriad Genetics, Inc. (Salt Lake City, UT, USA) evaluates tumor genome loss of heterozygosity, telomeric allelic imbalance (TAI), and large-scale state transitions, which are all indirect measures of tumor genomic instability. High HRD scores are highly correlated with defects in BRCA1/2 and are associated with sensitivity to neoadjuvant platinum-based chemotherapy in TNBC $[9,11]$. Another study examining TAI in sporadic TNBC has shown that tumors with high levels of TAI respond better to neoadjuvant platinum chemotherapy [7]. In addition to exhibiting genomic instability, tumors with BRCAness may exhibit characteristic gene expression patterns. Mulligan and colleagues [8] recently reported on a 44-gene DNA damage response deficiency signature (DDRDS) which was developed in cohorts enriched for germline BRCA1/2 and Fanconi anemia mutations. The DDRDS is enriched for immune responserelated genes and predicted favorable response to $\mathrm{FE}_{90} \mathrm{C}$ chemotherapy in both TNBC and hormone receptorpositive breast cancer. The aCGH, HRD, TAI, and DDRDS platforms are all compatible with FFPE tissues, making them suitable for prospective studies. Furthermore, all of these HR deficiency platforms suggest that the BRCAness phenotype exists in at least half of patients with TNBC and one quarter of patients with hormone receptorpositive breast cancer, implying future predictive applicability to a large fraction of patients with breast cancer.

There is now renewed interest in the efficacy of platinum agents for the treatment of TNBC as recent randomized trials have demonstrated improvement in pathological complete response rates with the addition of neoadjuvant carboplatin to anthracycline/taxanebased chemotherapy [12-14]. HR deficiency assay assessments on the completed randomized neoadjuvant platinum trials are eagerly awaited and will help identify patients most likely to benefit from such an approach. Whether HR deficiency assays will predict benefit from PARP inhibitors in addition to DNA-damaging chemotherapy also remains to be seen.

Employing functional measures of HR pathway deficiency rather than relying on documented changes in specific genes should capture more patients who might benefit from DNA-damaging therapies, and Vollebergh and colleagues should be congratulated on developing one such assay. However, before HR deficiency assays can be used for medical utility, the recognized steps for incorporation of predictive biomarkers into clinical care (that is, additional validation studies and assessment within prospective randomized trials) have to be fulfilled [15]. If appropriately validated, HR deficiency assays could have tremendous impact on patient care by identifying patients most likely to benefit from DNA-damaging agents like platinum salts or PARP inhibitors or both.

In conclusion, considerable strides have been made in analytical development and early clinical validation of functional HR deficiency assays and these efforts bring us one step closer to the eventual utilization of $B R C A$ ness as a guide to personalize treatment with DNAdamaging agents in patients with breast cancer.

\section{Abbreviations}

aCGH: Array comparative genomic hybridization; DDRDS: DNA damage response deficiency signature; DSB: Double-strand break; $\mathrm{FE}_{90} \mathrm{C}$ : 5fluorouracil-epirubicin-cyclophosphamide; FFPE: Formalin-fixed paraffin embedded; HD-CTC: High-dose cyclophosphamide-thiotepa-carboplatin; HR: Homologous recombination; HRD: Homologous recombination deficiency; PARP: Poly(ADP-ribose) polymerase; TAl: Telomeric allelic imbalance; TNBC: Triple-negative breast cancer.

\section{Competing interests}

PS receives research funding from GlaxoSmithKline (Uxbridge, UK), Myriad Genetics, Inc., Novartis (Basel, Switzerland), and Roche (Basel, Switzerland). SRS declares that he has no competing interests.

\section{Author details}

'Department of Pathology and Laboratory Medicine, University of Kansas Medical Center, 3901 Rainbow Boulevard, MS1016, Kansas City, KS 66160, USA. 'Division of Hematology/Oncology, Department of Internal Medicine, University of Kansas Medical Center, 2330 Shawnee Mission Parkway, MS5003, Westwood, KS 66205, USA.

Published: 24 July 2014

\section{References}

1. Vollebergh MA, Lips EH, Nederlof PM, Wessels LF, Wesseling J, Vd Vijver MJ, de Vries EG, van Tinteren H, Jonkers J, Hauptmann M, Rodenhuis S, Linn SC: Genomic patterns resembling BRCA1- and BRCA2-mutated breast cancers predict benefit of intensified carboplatin-based chemotherapy. Breast Cancer Res 2014, 16:R47.

2. Moynahan ME, Chiu JW, Koller BH, Jasin M: Brca1 controls homologydirected DNA repair. Mol Cell 1999, 4:511-518. 
3. Moynahan ME, Pierce AJ, Jasin M: BRCA2 is required for homology-directed repair of chromosomal breaks. Mol Cell 2001, 7:263-272.

4. Sharma P, Stecklein SR, Kimler BF, Klemp JR, Khan QJ, Fabian CJ, Tawfik OW, Connor CS, McGinness MK, Mammen JMV, Jensen RA: BRCA1 insufficiency is predictive of superior survival in patients with triple negative breast cancer treated with platinum based chemotherapy. Cancer Res 2012, 72:D09-02.

5. Byrski T, Gronwald J, Huzarski T, Grzybowska E, Budryk M, Stawicka M, Mierzwa T, Szwiec M, Wisniowski R, Siolek M, Dent R, Lubinski J, Narod S: Pathologic complete response rates in young women with BRCA1-positive breast cancers after neoadjuvant chemotherapy. J Clin Oncol 2010, 28:375-379.

6. Tutt A, Robson M, Garber JE, Domchek SM, Audeh MW, Weitzel JN, Friedlander M, Arun B, Loman N, Schmutzler RK, Wardley A, Mitchell G, Earl H, Wickens M, Carmichael J: Oral poly(ADP-ribose) polymerase inhibitor olaparib in patients with BRCA1 or BRCA2 mutations and advanced breast cancer: a proof-of-concept trial. Lancet 2010, 376:235-244.

7. Birkbak NJ, Wang ZC, Kim JY, Eklund AC, Li Q, Tian R, Bowman-Colin C, Li Y, Greene-Colozzi A, Iglehart JD, Tung N, Ryan PD, Garber JE, Silver DP, Szallasi Z, Richardson AL: Telomeric allelic imbalance indicates defective DNA repair and sensitivity to DNA-damaging agents. Cancer Discov 2012, 2:366-375.

8. Mulligan JM, Hill LA, Deharo S, Irwin G, Boyle D, Keating KE, Raji OY, McDyer FA, O'Brien E, Bylesjo M, Quinn JE, Lindor NM, Mullan PB, James CR, Walker SM, Kerr P, James J, Davison TS, Proutski V, Salto-Tellez M, Johnston PG, Couch FJ, Paul Harkin D, Kennedy RD: Identification and validation of an anthracycline/cyclophosphamide-based chemotherapy response assay in breast cancer. J Natl Cancer Inst 2014, 106:djt335.

9. Telli ML, Jensen KC, Kurian AW, Vinayak S, Lipson JA, Schackmann EA, Wapnir IL, Carlson RW, Sparano JA, Head B, Goldstein LJ, Hayler BB, Dakhil SR, Manola J, Ford JM: PrECOG 0105: final efficacy results from a phase II study of gemcitabine (G) and carboplatin (C) plus iniparib (BSI-201) as neoadjuvant therapy for triple-negative (TN) and BRCA $1 / 2$ mutation-associated breast cancer. J Clin Oncol 2013, Abstract:1003.

10. Lips EH, Mulder L, Hannemann J, Laddach N, Vrancken Peeters MT, van de Vijver MJ, Wesseling J, Nederlof PM, Rodenhuis S: Indicators of homologous recombination deficiency in breast cancer and association with response to neoadjuvant chemotherapy. Ann Oncol 2011, 22:870-876

11. Timms KM, Abkevich V, Neff C, Morris B, Potter J, Tran TV, Chen J, Sangale Z, Tikishvili E, Zharkikh A, Perry M, Gutin A, Lanchbury JS: Association between BRCA1/2 status and DNA-based assays for homologous recombination deficiency in breast cancer. Cancer Res 2013, 73:P6-05-10.

12. von Minckwitz G, Schneeweiss A, Loibl S, Salat C, Denkert C, Rezai M, Blohmer JU, Jackisch C, Paepke S, Gerber B, Zahm DM, Kümmel S, Eidtmann H, Klare P, Huober J, Costa S, Tesch H, Hanusch C, Hilfrich J, Khandan F, Fasching PA, Sinn BV, Engels K, Mehta K, Nekljudova V, Untch M: Neoadjuvant carboplatin in patients with triple-negative and HER2-positive early breast cancer (GeparSixto; GBG 66): a randomised phase 2 trial. Lancet Oncol 2014, 15:747-756.

13. Sikov WM, Berry DA, Perou CM, Singh B, Cirrincione C, Tolaney S, Kuzma CS, Pluard TJ, Somlo G, Port E, Golshan M, Bellon JR, Collyar D, Hahn OM, Carey $L A$, Hudis C, Winer EP: Impact of the addition of carboplatin $(\mathrm{Cb})$ and/or bevacizumab (B) to neoadjuvant weekly paclitaxel $(\mathrm{P})$ followed by dose-dense $A C$ on pathologic complete response $(p C R)$ rates in triple-negative breast cancer (TNBC): CALGB 40603 (Alliance). Cancer Res 2013, 73:S5-S01.

14. Rugo HS, Olopade Ol, DeMichele A, Vant Veer L, Buxton M, Hylton N, Yee D, Chien AJ, Wallace A, I-SPY 2 Site PI's, Lyandres J, Davis S, Sanil A, Berry D, Esserman L: Veliparib/carboplatin plus standard neoadjuvant therapy for high-risk breast cancer: first efficacy results from the I-SPY 2 TRIAL. Cancer Res 2013, 73:S5-S02

15. Simon RM, Paik S, Hayes DF: Use of archived specimens in evaluation of prognostic and predictive biomarkers. J Natl Cancer Inst 2009, 101:1446-1452.

\section{doi:10.1186/s13058-014-0409-7}

Cite this article as: Stecklein and Sharma: Tumor homologous recombination deficiency assays: another step closer to clinical application?. Breast Cancer Research 2014 16:409.

\section{Submit your next manuscript to BioMed Central and take full advantage of:}

- Convenient online submission

- Thorough peer review

- No space constraints or color figure charges

- Immediate publication on acceptance

- Inclusion in PubMed, CAS, Scopus and Google Scholar

- Research which is freely available for redistribution 